\title{
Sensitivity to sucrose in smokers and nonsmokers: A comparison of TSD and percent correct measures*
}

\author{
ELLIOTT D. PURSELL, RAYMOND E. SANDERS \\ University of Akron, Akron, Ohio 44325
}

\begin{abstract}
Ten smokers and 10 nonsmokers were compared for taste sensitivity to sucrose on two discrimination tasks, one at near-threshold (NT) concentration level and one at suprathreshold (ST) concentration level. The data were analyzed using the $d_{s}$ and area under ROC curve measures based on the theory of signal detection (TSD), and by using the percentage correct responses. Analysis of both TSD measures showed smokers to be significantly more sensitive than nonsmokers on the NT task and more sensitive on the ST task, but not significantly so. Comparison of mean percent correct responses showed no significant differences. A reflexive enhancement phenomenon was suggested as a possible interpretation. A decreased sensitivity to the bitter taste in smokers apparently results in an increased sensitivity to the sweet taste.
\end{abstract}

Some recent studies of taste sensitivity have successfully employed the theory of signal detection (TSD) in studying such problems as sensitivity before and after eating (Moore, Linker, \& Purcell, 1965) and the relative capacity of several theories of sensory discrimination to encompass taste discrimination data (Linker, Moore, \& Galanter, 1964). As Swets (1961) has pointed out, the application of TSD to taste discrimination data produces an unconfounded measure of sensory capability which is independent of the response criterion. This is in contrast with more traditional psychophysical methods in which measures of sensitivity such as absolute threshold are confounded with the S's response criterion.

A phenomenon generally considered to influence taste sensitivity is cigarette smoking. Studies comparing the taste sensitivity of cigarette smokers with that of nonsmokers have typically reported either no differences or a decrement in sensitivity in smokers (e.g., Arfmann \& Chapanis, 1962: Pangborn, Trabue, \& Barylko-Pikielna, 1967). A decrement in sensitivity in smokers to bitter-tasting stimuli has frequently been found (e.g., Kaplan, Glanville, \& Fischer, 1964, 1965), while differential sensitivity to sweet, sour, or salty stimuli has not been consistently reported (Pangborn et al, 1967).

The literature concerning the influence of smoking on taste sensitivity contains striking differences, from study to study, in procedures and design. Most such studies have used traditional psychophysical methods, apparently with the implicit assumption that the various specific methods are equivalent. Such an assumption may be untenable when the differences in methodology are closely examined (Richter \& Campbell, 1940).

\footnotetext{
*This article is based on a thesis submitted by E.D.P. in partial fulfillment of requirements for the MA degree.

$\div$ Requests for reprints should be sent to Raymond E. Sanders, Department of Psychology, University of Akron, Akron, Ohio 44325.
}

The purpose of the present study was to compare the capacity of two TSD measures of sensitivity (area under the ROC curve and $d_{s}$ ) with the percent correct response measure in detecting possible differences between smokers and nonsmokers in sensitivity to the taste of sucrose. Sucrose was selected on the basis of fewer reported complications regarding adaptation to the sweet taste (i.e., slower adaptation time than to salt) and longer retention of appeal and acceptability than other taste stimuli (Kocher \& Fisher, 1969; Krakauer \& Dallenbach, 1937).

\section{METHOD}

\section{Subjects}

Twenty volunteer Ss, 18 to 28 years of age, were employed. All were enrolled at the University of Akron. Ten Ss $(5$ males and 5 females) were smokers, and 10 ( 5 males and 5 females) were nonsmokers. Smokers were those who smoked 20 or more cigarettes per day and had been smoking for a minimum of 2 years. Nonsmokers were individuals who had not smoked at all in the past 6 months and had never smoked regularly.

\section{Materials and Apparatus}

The experiment was conducted in a relatively odor-free room at a temperature of $70^{\circ} \pm 2^{\circ} \mathrm{F}$. Three contiguous booths, each with a chair, were provided for the Ss. Ss were separated from each other by the sides of the booths, and from the $E$ by the backs of the booths. Stimulus solutions were presented through a small opening in the back of each booth. Each booth was equipped with two response buttons, one button labeled $S$ (to designate either sucrose or strong) and the other $W$ (for water or weak). Napkins, distilled water, a rinse glass, and a cuspidor were also provided in each booth.

Four different stimulus solutions were used in the course of the experiment. Two were designated near-threshold (NT). Of these NT solutions, one was distilled water and the other was a weak sucrose solution $(0.20 \% ; 0.0058 \mathrm{M})$. The other two stimulus solutions were designated as suprathreshold (ST). The weaker of the two ST solutions contained $9.0 \%(0.2740 \mathrm{M})$ sucrose; the stronger contained $10.0 \%(0.3041 \mathrm{M})$ sucrose. Judgments or comparisons were made only between members of the NT pair and between members of the ST pair. No NT solution was compared with any ST solution. 
Table 1

Means and Standard Deviations for Area Under ROC Curve, $d_{s}$, and Percent Correct Sensitivity Measures

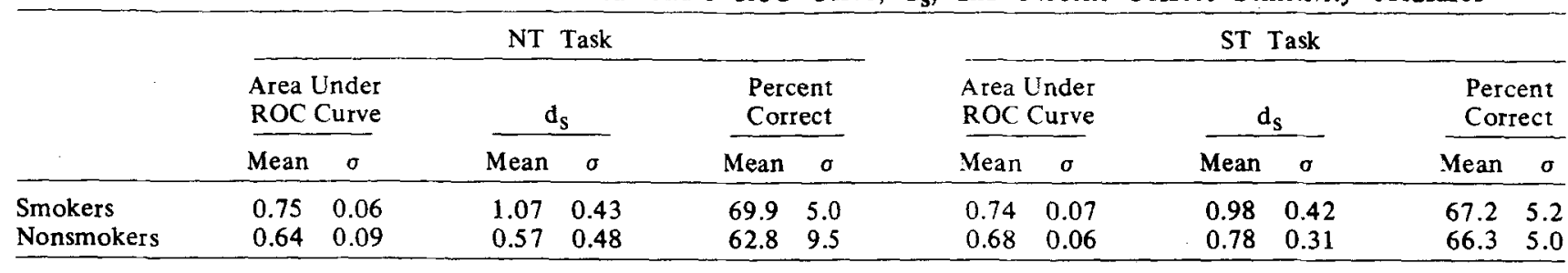

Response sheets employing a 6-point scale for each response were used. For the NT solutions, a scale value of 1 indicated a certainty of water; 2 = probably water; 3 = guessing water; $4=$ guessing sucrose; $5=$ probably sucrose; $6=$ certainty of sucrose. For the ST solutions, the same scale values were used except that $1=$ certainty of the weaker solution, and $6=$ certainty of the stronger solution.

\section{Procedure}

All Ss performed two tasks, one involving discrimination between the NT solutions and the other involving discrimination between the ST solutions. Each $\mathrm{S}$ received 70 trials per session for two sessions on the NT task, and a like number for the ST task. Half the Ss in each group (smokers vs nonsmokers) received the tasks in the NT-ST order; the order was reversed for the remaining Ss. Testing occurred between $9 \mathrm{a} . \mathrm{m}$. and 12 noon for half the $S$ s, and between 1 p.m. and 4 p.m. for the other half.

Prior to each test session. the Ss received instructions which described solution presentation procedures and probabilities $(\mathrm{p}=$ 0.50 ) of occurrence, use of the response sheet, and response procedures. For each trial, the $S s$ received $5 \mathrm{cc}$ of solution, which was the amount used for all concentrations. The NT solutions (i.e.. $0.20 \%$ sucrose and distilled water) were presented randomly. one solution per trial. The same presentation procedure was used for the ST solutions. Ss were instructed to sip and allow the $5 \mathrm{cc}$ of liquid to contact as much of the tongue as possible and to swallow the liquid. Six training trials preceded each session to allow for familiarization and warm-up effects, with each solution presented three times and feedback provided to the Ss. On test trials, the Ss were first required to decide upon a response category of either water or sucrose for the NT task and, similarly, either weak sucrose or strong sucrose for the ST task. The Ss then indicated their degree of confidence in their judgment by marking on the response sheet one of the three alternatives corresponding to the chosen response category. Immediately after the written response, the Ss pressed one of the two buttons to indicate their chosen response category. For the NT solutions, a press of the $\mathrm{W}$ button indicated a choice of any of the three water alternatives on the 6-point scale, and a press of the $S$ button indicated a choice of any of the three sucrose alternatives. For the ST solutions, a press of the $W$ button indicated a choice of any of the three weak sucrose alternatives on the 6-point scale, and a press of the $S$ button indicated a choice of any of the three strong sucrose alternatives. The feedback light was then lighted automatically for a correct response. Following feedback, the $S$ filled the rinse glass, rinsed fully, and then expectorated into his cuspidor. Rinsing occurred during the initial part of a $20-\mathrm{sec}$ intertrial interval.

\section{RESULTS}

The means and standard deviations for the area under ROC curve, $d_{s}$, and percent correct measures are shown in Table 1. Each mean score is based on 140 judgments per $\mathrm{S}$. On both area under ROC curve and $\mathrm{d}_{\mathrm{s}}$ measures, smokers were significantly more sensitive than were nonsmokers on the NT task $(\mathrm{t}=3.54, \mathrm{p}<.01$, and $\mathrm{t}=$ $2.45, \mathrm{p}<.05$, for ROC areas and $\mathrm{d}_{\mathrm{s}}$, respectively). Smokers showed greater sensitivity than nonsmokers on the ST task, but the differences with both measures (ROC curve and $d_{s}$ ) were not statistically reliable. Similar analyses, using the percent correct measure, yielded no significant differences between smokers and nonsmokers on either the NT or the ST task.

Inspection of each S's data for the first and second test sessions revealed that 9 of 10 smokers' performance improved in the second session relative to the first. Comparable figures for the 10 nonsmokers showed two individuals' performance improving, the performance of 7 Ss declining, and $1 \mathrm{~S}$ showing no change. A chi-square analysis of the above frequencies indicated that the differential tendency for smokers' performance to improve and for nonsmokers' performance to decline was significant $\left(\chi^{2}=7.3, \mathrm{df}=1, \mathrm{p}<.01\right)$, although no such tendency was apparent between the third and fourth sessions. To evaluate whether practice effects may have produced the improvement in smokers' performance, separate $d_{s}$ values and areas under the ROC curve for the first 15 trials and last 15 trials of the first session were compared. No significant differences were found in either case.

\section{DISCUSSION}

The results of this study show that the theory of signal detection (TSD) provided more sensitive measures of sensory discrimination ( $d_{s}$ and ROC curve areas) than a measure expressed in terms of percent correct. Significant differences between smokers and nonsmokers were found for both $d_{s}$ and ROC curve area measures on the NT task, and moderate but not significant differences were found on the ST task. In contrast with these findings, percent correct measures showed no significant differences for either task (NT and ST).

The direction of the differences observed between the groups showed smokers to be more sensitive to sucrose than nonsmokers. This result is consistent with the increase in sensitivity to sucrose in smokers from Session 1 to Session 2. No such increase was found in nonsmokers. A practice effect in smokers does not seem likely, since the sensitivity in this group, as reflected in $\mathrm{d}_{\mathrm{s}}$ and ROC curve areas, did not increase significantly in the last 15 trials of Session 1 compared with the first 15 trials of Session 1. No increase in sensitivity between 
Sessions 3 and 4 was found for either group. No motivational differences between the smokers and nonsmokers were observed, despite careful attention to such a possibility, and an explanation for the increase in sensitivity in smokers between Sessions 1 and 2 is not immediately apparent.

The relatively small number of Ss tested makes it difficult to suggest that all smokers are more sensitive than nonsmokers to the taste of sucrose. Nevertheless, at least in regard to the data in this study, some comment on this finding seems warranted. A possible explanation for this effect involves a reflexive enhancement phenomenon. Troland (1930) reported that a decrease in sensitivity to one taste quality frequently produces an increase in sensitivity for another taste quality. In this study, the exposure of smokers to bitter taste stimuli contained in cigarette smoke may be implicated. Also, previous studies have reported that smokers are less sensitive to bitter tastes. Since smokers frequently experience a sensation of bitter and acid tasting compounds which are normal components of tobacco smoke (Fischer et al, 1963, p. 164), it seems reasonable to expect that they will become accustomed to, or adapt to, these tastes. Reflexive enhancement, which first involves adaptation to continued presentation of a stimulus followed by an increase in sensitivity to qualitatively different stimuli within the same modality, is known to occur for taste stimuli (Allen \& Weinberg, 1925). The findings of the present study conform to such an interpretation involving adaptation and decreased sensitivity to bitter tastes and a reflexive enhancement of sensitivity to sweet tastes.

In general, this study supports the notion that the methodology employed in measuring taste sensitivity is an important factor, and that TSD measures of sensitivity appear to be superior to such measures as percent correct responses. Moreover, the unconfounded TSD measures offer the possibility of clarifying what seem to be unexpectedly complicated effects of smoking on taste sensitivity. If further support for these findings is forthcoming, it will not be possible to characterize the effects of smoking on taste sensitivity as a general increase or decrease, but more limited and specific statements will be required.

\section{REFERENCES}

Allen, F., \& Weinberg, M. The gustation sensory reflex. Quarterly Journal of Experimental Physiology, 1925, 15, $385-420$.

Arfman, B. L., \& Chapanis, N. P. The relative sensitivities of taste and smell in smokers and non-smokers. Journal of General Psychology, 1962, 66, 315-320.

Fischer, R., Griffin, F., \& Kaplan, A. R. Taste thresholds, cigarette smoking, and food dislikes. Medicina Experimentalis, $1963,9,151-167$.

Kaplan, A. R., Glanville, E. V., \& Fischer, R. Taste thresholds for bitterness and cigarette smoking. Nature, 1964, 202, 1366.

Kaplan, A. R., Glanville, E. V., \& Fischer, R. Cumulative effects of age and smoking on taste sensitivity in males and females. Journal of Gerontology, 1965, 20, 334-337.

Kocher, E. C., \& Fisher, G. L. Subjective intensity and taste preference. Perceptual \& Motor Skills, 1969, 28, 735-740.

Krakauer, D., \& Dallenbach, K. M. Gustatory adaptation to sweet, sour, and bitter. American Journal of Psychology, $1937,49,469-475$.

Linker, E., Moore, M. E., \& Galanter, E. Taste thresholds, detection models and disparate results. Journal of Experimental Psychology, 1964, 67, 59-66.

Moore, M. E., Linker, E., \& Purcell, M. Taste-sensitivity after eating: A signal-detection approach. American Journal of Psychology, 1965, 78, 107-111.

Pangborn, R. M., Trabue, I. M., \& Barylko-Pikielna, N. Taste, odor, and tactile discrimination before and after smoking. Perception \& Psychophysics, 1967, 2, 529-532.

Richter, C. P., \& Campbell, K. H. Sucrose taste thresholds of rats and humans. American Journal of Physiology, 1940, 128, 291-297.

Swets, J. A. Is there a sensory threshold? Science, 1961, 134, 168-177.

Troland, L. T. The principles of psychophysiology. Vol. II. Sensation. New York: Van Nostrand, 1930.

(Received for publication November 15, 1972; revision received March 9, 1973.) 